\title{
Determinação de cistatina C como marcador de função renal
}

\author{
Cystatin C measurement as renal function marker
}

Letícia Aparecida Lopes Neri'; Maria Elizabeth Mendes²; Elias David-Neto ${ }^{3}$; Nairo Massakasu Sumita4; Flávia Silva Medeiros ${ }^{5}$

\begin{abstract}
unitermos Cistatina

Nefelometria

Função renal

Transplante

Imunossupressores

\section{resumo}

Introdução: A cistatina C sérica tem sido apontada como um marcador de filtração glomerular. Objetivo: Realizar a validação de um método específico e automatizado, a imunonefelometria, mensurando os níveis séricos de cistatina C por meio do nefelômetro da empresa Behring (BN II) e correlacionar resultados obtidos entre pacientes transplantados. $O$ ensaio perfaz o intervalo de referência de 0,23-7,25 mg/l. A imprecisão intra e interensaio foi de $8,73 \%$ e 5,38\%, respectivamente. A recuperação analítica da cistatina $C$ após adição de controle foi entre $86,7 \%$ e $98 \%$ (média 92,3\%). A estabilidade da cistatina $\mathrm{C}$ à temperatura ambiente, sob refrigeração e sob congelamento foi testada. A perda mais significativa foi encontrada nas amostras armazenadas à temperatura ambiente, em que foram perdidos até $10 \%$ da concentração inicial. Foi encontrado coeficiente de variação de $14,79 \%$ para sensibilidade analítica. Durante todo o processo foram comparados os resultados com o controle de qualidade e obtivemos bons resultados. Depois desses testes, nós comparamos as correlações em três grupos de pacientes transplantados renais sob diferentes esquemas de imunossupressão $(n=197)$ - azatioprina $(n=36)$, micofenolato mofetil $(n=131)$ e sirolimus $(n=30)$ - entre as equações de estimativa de filtração glomerular (Cockroft Gault, Nankivell e Modification of Diet in Renal Disease) e cistatina C sérica ou creatinina sérica. Conclusão: $O$ ensaio nefelométrico cistatina $C$ pode perfeitamente ser adequado à nossa rotina laboratorial e as correlações entre creatinina sérica e as diferentes equações de estimativa de filtração glomerular são melhores do que quando comparamos as mesmas à cistatina $\mathrm{C}$ nos três grupos, independentemente da terapia imunossupressora utilizada.
\end{abstract}

\section{abstract}

Introduction: Serum cystatin C has been identified as a glomerular filtration marker. Objective: To validate immunonephelometry, a specific and automated method, by measuring levels of serum cystatin $C$ through Behring nephelometer (BN II) and correlate results among transplant patients. The assay comprises the reference range of 0:23 to 7:25 $\mathrm{mg} / \mathrm{l}$. The intra-assay and inter-assay imprecision rates were $8.73 \%$ and $5.38 \%$, respectively. The analytical recovery of cystatin C after addition of control was between $86.7 \%$ and 98\% (average 92.3\%). The stability of cystatin C to room temperature, refrigerated or frozen was tested. The most significant loss was found in samples stored at room temperature, in which up to $10 \%$ of the initial concentration was lost. The coefficient of variation was $14.79 \%$ for analytical sensitivity. Throughout the process the results were compared with quality control and good results were achieved. After these tests, we compared the correlations between equations for estimating glomerular filtration rate (Cockroft Gault, Nankivell and MDRD) and serum cystatin C or serum creatinine in three groups of kidney transplant patients under different immunosuppressive regimens ( $\mathrm{n}=197)$ [azathioprine $(\mathrm{n}=36)$, mycophenolate mofetil $(\mathrm{n}=131)$ or sirolimus $(\mathrm{n}=30)]$. Conclusion: The nephelometric cystatin C assay may be perfectly suitable for our routine laboratory. The correlations between serum creatinine and the various equations for estimating glomerular filtration are better than those between cystatin $C$ and equations for estimating glomerular filtration in the three groups irrespective of the immunosuppressive therapy used. key words

Cystatin

Nephelometry

Renal function

Transplantation

Imunosupressor

1. Mestra em Ciências; farmacêutica do Hospital das Clínicas da Faculdade de Medicina da Universidade de São Paulo (HCFMUSP).

2. Doutora em Patologia; médica-chefe do HCFMUSP.

3. Livre-docente em Nefrologia; professor do HCFMUSP.

4. Doutor em Patologia; diretor técnico do HCFMUSP.

5. Doutora em Nefrologia; professora da Faculdade de Medicina de Jundiaí. 
A introdução de um marcador mais sensível que a creatinina sérica na prática clínica poderia favorecer o diagnóstico precoce da injúria renal, possibilitando condutas terapêuticas mais eficientes e que possam aumentar a sobrevida do órgão com disfunção(22, 29, 32, 33, 47, 50, 52, 66, 67, 74, 76).

Desde 1985, vários estudos têm observado a relação entre a cistatina $\mathrm{C}$ e o ritmo de filtração glomerular (RFG) em diversas populações, inclusive receptores de transplante renal, e têm apontado a cistatina $C$ como marcador de função renal superior ou, pelo menos, igual à creatinina sérica, até mesmo quando se avaliam pacientes receptores de enxerto renal $\left.\right|^{(14,16,21,61,63,69)}$.

A cistatina $C$ é uma proteína inibidora das proteases e pode ser mensurada no soro ou no plasma humano. As proteinases ou proteases são enzimas cuja atividade é regulada por seus inibidores, entre eles a cistatina $C$, e estão envolvidas no processo de degradação proteica intra e extracelular e em uma variedade de reações metabólicas ${ }^{(71)}$.

A cistatina $C$, também conhecida como traço gama e pós-gama-globulina, é uma proteína não glicada, de baixo peso molecular $(13,36 \mathrm{kDa})$, produzida de forma contínua e estável por todas as células nucleadas, com elevada concentração em nível extracelular e com importante atividade antiviral $(30,48,72)$. A cistatina $C$ é filtrada livremente pelo glomérulo renal, sendo a seguir reabsorvida, catabolizada e degradada em peptídeos menores, e seus aminoácidos constituintes, pelas células do túbulo proximal(25).

Os principais atributos da cistatina $\mathrm{C}$, como marcador bioquímico para avaliação da filtração glomerular, são o pequeno tamanho e o alto ponto isoelétrico de 9,3, características essas que facilitam a filtração através da membrana glomerular ${ }^{(20,31)}$. Assim, a concentração sérica dependerá quase exclusivamente da capacidade de filtração glomerular ${ }^{(56)}$.

Diferentemente da dosagem de ureia e creatinina, a concentração sérica da cistatina $C$ não sofre influência do volume da massa muscular, do sexo ou da alimentação. Após 1 ano de idade, a concentração de cistatina $C$ torna-se estável. Estudos em populações pediátricas ainda são escassos, sendo algumas referências contraditórias em relação à viabilidade da utilização desse marcador para avaliação da função renal em crianças. No entanto, em crianças, a determinação de cistatina $C$ parece ser, pelo menos, equivalente à creatinina sérica ${ }^{(7,10,26,35,39,41,45,57,58,60,68,73) \text {. Sua produção }}$ parece não ser afetada por processos inflamatórios ou estados febris $(4,6,18,24,38,67,70)$.

A amostra de soro pode ser armazenada a $4^{\circ} \mathrm{C}$ ou congelada durante seis meses sem perda apreciável na concentração da cistatina C. No liquor, essa proteína pode ser degradada de forma rápida, possivelmente pela ação das serinas proteases produzidas por microrganismos contaminantes ou pela liberação das enzimas dos granulócitos durante o processo inflamatório ${ }^{(1,15,37)}$.

A dosagem no plasma heparinizado também é adequada. A turbidez da amostra pode prejudicar o ensaio, tanto na amostra de plasma quanto no soro, por tratar-se de fator interferente para a nefelometria e a turbidimetria.

Várias metodologias já foram empregadas para a determinação da cistatina $C$, como enzimaimunoensaio (EIA), radioimunoensaio (RIA), fluoroimunoensaio e imunodifusão radial (RID) simples, porém ainda não estão adequadamente padronizadas ${ }^{(51,65)}$.

O primeiro ensaio para quantificar a cistatina $\mathrm{C}$ foi o RIA, em 1979, e tinha como limite de detecção a concentração de $30 \mu \mathrm{g} / \mathrm{l}$, nível suficiente para detectar a cistatina $C$ no soro de indivíduos saudáveis. Posteriormente, novas técnicas foram desenvolvidas, alcançando limites de detecção entre 0,13 e $0,19 \mu \mathrm{g} / \mathrm{I}^{(43,44)}$.

A imprecisão analítica da determinação sérica de cistatina $C$ foi estimada em 1,2 e 5,5\% (coeficiente de variação [CV] interensaio) para concentrações de 5,28 e 0,97 mg/l, respectivamente, por ensaio imunoturbidimétrico ${ }^{(5)}$.

\section{Materiais e métodos}

O estudo foi delineado em duas fases, denominadas fase $A$ e fase B. Na primeira, procedemos à validação do método imunonefelométrico para dosagem sérica de cistatina $C$ na Divisão de Laboratório Central do Hospital das Clínicas da Faculdade de Medicina da Universidade de São Paulo (DLC-HCFMUSP). $\mathrm{Na}$ fase $\mathrm{B}$, avaliamos a cistatina $\mathrm{C}$ e a creatinina como marcadores de função renal em pacientes transplantados renais, que estavam sob diferentes esquemas de imunossupressão.

$\mathrm{Na}$ fase $\mathrm{A}$, as amostras foram analisadas pelo conjunto diagnóstico para cistatina $\mathrm{C}$ da marca Dade Behring $(\mathrm{GmbH}$, Marburg, Alemanha). Foram utilizados os controles nível 1 (valor normal) e nível 2 (valor patológico) procedentes do mesmo conjunto diagnóstico desse fabricante durante os testes de validação.

Foi empregado um homogeneizado de amostras de soro de pacientes transplantados renais estáveis sob acompanhamento na Unidade de Transplante Renal (UTR) do HCFMUSP.

Nas análises laboratoriais, foram aplicados os critérios de validação embasados nas normas nacionais e internacionais: Agência Nacional de Vigilância Sanitária (ANVISA), Clinical 
Laboratory Improvement Act (CLIA) e Clinical and Laboratory

Standards Institute (CLSI) $(2,9,11-13,34,36,46,49,53-55)$.

$\mathrm{Na}$ fase $\mathrm{B}$, foram selecionados pacientes transplantados renais aleatórios da UTR-HCFMUSP que obedecessem aos critérios de inclusão e não apresentassem nenhum critério de exclusão.

\section{Critérios de inclusão:}

- pacientes transplantados renais, sem distinção do tempo pós-transplante;

- anuência ao termo de consentimento livre e esclarecido (TCLE);

- idade acima de 18 anos.

\section{Critérios de exclusão:}

- transplante múltiplo;

- portadores de hepatopatias;

- terapia tireoidiana;

- portadores de neoplasia;

- pulsoterapia com metilprednisolona há menos de um mês.

Esses pacientes selecionados foram agrupados de acordo com o esquema imunossupressor em uso na data da coleta do exame de cistatina $C$ e creatinina sérica. A Tabela 1 descreve a distribuição dos pacientes por grupos.

Esses pacientes foram submetidos a uma única coleta de $5 \mathrm{ml}$ de sangue total em tubo sem anticoagulante, da qual foi separado o soro após retração de coágulo. Esse material foi submetido às dosagens de cistatina $\mathrm{C}$ e creatinina séricas.

\begin{tabular}{cc} 
& $\begin{array}{l}\text { Distribuição dos pacientes em grupos, } \\
\text { segundo esquema de medicação } \\
\text { imunossupressora }\end{array}$ \\
\hline Tabela 1 & Imunossupressão \\
\hline Grupo & AZA \\
G1 - AZA & AZA/CYA \\
& AZA/TAC \\
G2 - MMF & MMF/CYA \\
& MMF/TAC \\
& SRL/AZA \\
G3 - SRL & SRL \\
& SRL/CYA \\
& SRL/TAC \\
& SRL/MMF \\
\hline
\end{tabular}

AZA: azatioprina; CYA: ciclosporina; TAC: tacrolimus; MMF: micofenolato mofetil; SRL: sirolimus.
Com base nesses resultados, foram calculados a depuração de creatinina, utilizando-se a equação de Cockroft Gault (CG), e o RFG, por meio das equações de Nankivell (NK) e Modification of Diet in Renal Disease (MDRD).

As amostras foram coletadas nas dependências da DLC-HCFMUSP e na Divisão de Urologia do HCFMUSP e as análises de cistatina $C$ sérica e creatinina sérica foram realizadas no Serviço de Bioquímica Clínica da DLC-HCFMUSP. Os testes para avaliação do ensaio de creatinina sérica foram desenvolvidos no Laboratório Central previamente, quando foi padronizada essa análise.

FASE A:

Validação da Metodologia Nefelométrica para Dosagem da Cistatina C

\section{Calibração}

A calibração do sistema analítico foi realizada com o soro calibrador do conjunto diagnóstico, e as curvas de calibração foram obtidas por meio de múltiplos pontos.

As diluições foram realizadas a partir do padrão concentrado de cistatina $C$ de $1,40 \mathrm{mg} / \mathrm{dl}$ nas seguintes proporções: $1 / 20,1 / 40,1 / 180,1 / 160,1 / 320$ e 1/640. Quando a curva de calibração não era adequada, o equipamento sinalizava com cor vermelha na área de trabalho da tela do monitor.

\section{Precisão}

A precisão foi estudada adotando-se os controles de qualidade presentes no conjunto reagente com concentrações de 0,90 mg/l (nível 1) e 1,80 mg/l (nível 2).

A utilização de um homogeneizado de amostras de soro de pacientes transplantados renais estáveis tinha como objetivo evitar o efeito de matriz para o estudo da precisão intra e interensaio.

Em todos os testes de validação, foram calculadas as médias, os desvios padrão (DP) e os CVs dos valores obtidos. Os cálculos foram efetuados no programa Excel, versão 5.0 (Microsoft ${ }^{\circledR}$, Windows XP, EUA).

Avaliou-se a precisão intraensaio por meio da análise, no mesmo dia, de 30 replicatas dos dois níveis de controle e 10 replicatas de conjunto homogeneizado de amostras $(n=30)$ contendo concentração conhecida de cistatina C na faixa de referência.

Foram dois ensaios em dois lotes de amostras no mesmo dia para minimizar erros devido à presença de interferentes, como variação de corrente elétrica e temperatura. 
A precisão interensaio foi determinada em 30 dias, sendo realizada a análise dos dois níveis de controle em replicata a cada dia. Foi dosada amostra contendo concentração conhecida de cistatina $\mathrm{C}$ durante 30 dias consecutivos em duas corridas ao dia.

\section{Limite de deteç̧ão e sensibilidade analítica}

O limite de detecção foi determinado após a dosagem do branco do reativo em 20 replicatas. O CV considerado adequado é de $20 \%$ entre as leituras em replicata.

A sensibilidade analítica foi avaliada por meio de diluições seriadas de uma mesma amostra (calibrador de concentração $1,49 \mathrm{mg} / \mathrm{l}$ de cistatina $\mathrm{C}$ ) até a verificação do menor valor detectável pelo método, com $\mathrm{CV}$ entre as dosagens inferior a $15 \%$.

\section{Linearidade e estabilidade}

A estabilidade da amostra foi verificada em material armazenado previamente ( $n=10$ para cada homogeneizado de amostras) e com valor conhecido de concentração, estocado em câmara fria a $-20^{\circ} \mathrm{C}$. Foram realizadas as dosagens em 7, 30, 60 e 90 dias, e os resultados foram analisados em termos percentuais de perda em relação à concentração obtida no tempo zero.

A estabilidade da amostra à temperatura ambiente foi avaliada após 1, 3, 5 e 7 dias e também foi estocada sob refrigeração (entre 2 e $8^{\circ} \mathrm{C}$ ) por 1, 3, 5, 7, 14, 21 e 28 dias, dosando-se a cistatina $\mathrm{C}$ após esses períodos. Esse teste foi considerado aceitável quando a perda foi inferior a 10\% do valor inicial.

\section{Recuperação}

Estudou-se a recuperação do método adicionando soro controle de valor conhecido, em dois níveis, a um conjunto de 10 amostras de soro, previamente homogeneizadas, cuja concentração de cistatina $C$ também era conhecida. Foi estabelecido o percentual de recuperação após a adição citada em relação ao valor esperado.

\section{Controle da qualidade}

O controle da qualidade foi realizado em cada lote de dosagens das amostras, com os controles de qualidade do conjunto reagente. Esses controles contemplam faixas analíticas baixa e alta. Os resultados obtidos, necessariamente, deveriam estar no intervalo da média $\pm 2 \mathrm{DP}$ estabelecidos pelo fabricante. $O$ controle da qualidade garantiu a precisão do processo durante todo o estudo.

Ao final do experimento, foi calculado o CV entre todas as dosagens de controles.

\section{Testes estatísticos}

A análise estatística foi realizada no programa informatizado SPSS 10.0 for Windows College Station, Texas, 77845, EUA, e Microsoft Excel 2002, EUA, com nível de significância de $5 \%(p<0,05)$.

As análises descritivas das variáveis paramétricas foram realizadas calculando-se a média, o DP e o CV. Os resultados foram expressos por meio desses parâmetros.

Os dados não paramétricos foram analisados utilizandose o teste Qui-quadrado e a análise de regressão linear foi utilizada para avaliar o nível de concordância entre as medidas.

\section{Resultados}

\section{Precisão}

Na Tabela 2 estão descritos os valores de média, DP e CV observados na avaliação da precisão intra e interensaio do método imunonefelométrico para dosagem de cistatina $\mathrm{C}$.

\begin{tabular}{|c|c|c|c|c|c|c|c|}
\hline abela 2 & \multicolumn{7}{|c|}{$\begin{array}{l}\text { Resultados obtidos para avaliação da precisão intraensaio e interensaio (CV\%) nos dois níveis de } \\
\text { controle e soro de pacientes }(n=30)\end{array}$} \\
\hline \multirow{2}{*}{\multicolumn{2}{|c|}{ Concentração ( $\mu \mathrm{g} / \mathrm{ml})$}} & \multicolumn{3}{|c|}{ Intraensaio } & \multicolumn{3}{|c|}{ Interensaio } \\
\hline & & $\begin{array}{l}\text { Média } \\
(\mu g / m l)\end{array}$ & DP & CV (\%) & $\begin{array}{l}\text { Média } \\
(\mu g / \mathrm{ml})\end{array}$ & DP & CV (\% \\
\hline Controle 1 & 0,98 & 0,99 & 0,09 & 8,73 & 1,01 & 0,05 & 5,38 \\
\hline Controle 2 & 1,99 & 1,97 & 0,07 & 3,32 & 1,99 & 0,14 & 7,22 \\
\hline Soro & 1,00 & 1,01 & 0,09 & 8,93 & 1,02 & 0,01 & 8,20 \\
\hline
\end{tabular}

DP: desvio padrão; CV: coeficiente de variação. 
O CV intraensaio variou de $3,32 \%$ a $8,93 \%$ e o interensaio de $5,38 \%$ a $8,20 \%$.

\section{Limite de deteç̧ão e sensibilidade analítica}

Na Tabela 3 estão descritos os resultados obtidos nos testes de sensibilidade analítica e de limite de detecção. Como pode ser verificado, foi obtido CV de $14,79 \%$ e $8,25 \%$, respectivamente.

\begin{tabular}{|c|c|c|c|}
\hline $\begin{array}{ll} & \text { Li } \\
\text { Tabela } 3 & \text { an }\end{array}$ & \multicolumn{3}{|c|}{$\begin{array}{l}\text { Limite de detecção e sensibilidade } \\
\text { analítica }(n=10)\end{array}$} \\
\hline & $\begin{array}{l}\text { Média } \\
(\mathrm{mg} / \mathrm{l})\end{array}$ & $\begin{array}{c}\mathrm{DP} \\
(\mathrm{mg} / \mathrm{l})\end{array}$ & $\begin{array}{l}\mathrm{CV} \\
(\%)\end{array}$ \\
\hline $\begin{array}{l}\text { Limite de } \\
\text { detecção }\end{array}$ & 0,04 & 0,03 & 8,25 \\
\hline $\begin{array}{l}\text { Sensibilidade } \\
\text { analítica }\end{array}$ & 0,05 & 0,09 & 14,79 \\
\hline
\end{tabular}

\section{Estabilidade da amostra}

Os resultados da avaliação da estabilidade da amostra foram descritos nas Tabelas 4, 5 e $\mathbf{6}$. As concentrações médias das amostras utilizadas foram 1,01 mg/l, 1,48 mg/l e 3,34 mg/l.

$\mathrm{Na}$ Tabela 4 verificou-se que as amostras conservadas sob congelamento, à temperatura de $-20^{\circ} \mathrm{C}$, tiveram perda de apenas $0,2 \%$ de sua concentração inicial após 90 dias de armazenamento. Enquanto sob refrigeração, como pode ser verificado na Tabela 5, em 28 dias foram obtidas perdas de até $11,42 \%$.

\section{Percentual de perda da concentração} de cistatina $\mathrm{C}$ em relação ao tempo 0 Tabela 4 (estabilidade da amostra a $-20^{\circ} \mathrm{C}$ )

\begin{tabular}{ccccc}
\hline $\begin{array}{c}7 \text { dia } \\
(\%)\end{array}$ & $\begin{array}{c}7 \text { dias } \\
(\%)\end{array}$ & $\begin{array}{c}30 \text { dias } \\
(\%)\end{array}$ & $\begin{array}{c}60 \text { dias } \\
(\%)\end{array}$ & $\begin{array}{c}90 \text { dias } \\
(\%)\end{array}$ \\
0 & 0,03 & 0,06 & 0,11 & 0,19 \\
0 & 0 & 0,01 & 0,05 & 0,09 \\
0 & 0 & 0,01 & 0,05 & 0,06 \\
\hline
\end{tabular}

Tabela 6

Percentual de perda da concentração de cistatina $\mathrm{C}$ em relação ao tempo 0 (estabilidade da amostra à temperatura ambiente $\left.\left[22^{\circ} \mathrm{C}\right]\right)$

\begin{tabular}{cccc}
1 dia $(\%)$ & 3 dias (\%) & 5 dias (\%) & 7 dias $(\%)$ \\
0,67 & 0,74 & 3,81 & 8,94 \\
0,74 & 0,82 & 4,91 & 7,96 \\
0,78 & 0,93 & 2,96 & 9,98 \\
\hline
\end{tabular}

A maior perda foi obtida quando as amostras foram armazenadas à temperatura ambiente (Tabela 6), em que houve perda de até $10 \%$ de concentração de cistatina $C$ com relação à amostra inicial em apenas sete dias.

\section{Recuperação}

Os resultados do teste de recuperação (Tabela 7) oscilaram entre $86,7 \%$ e $98 \%$ de obtenção do analito cistatina $\mathrm{C}$ com relação à concentração inicial (antes da adição do controle comercial).

Teste de recuperação após adição do controle comercial de concentração conhecida níveis 1 e 2 a homogeneizado

Tabela 7 de amostras $(n=10)$

\begin{tabular}{cccc}
\hline Analito & $\begin{array}{c}\text { Concentração } \\
\text { esperada } \\
(\mathrm{mg} / \mathrm{l})\end{array}$ & $\begin{array}{c}\text { Concentração } \\
\text { obtida } \\
(\mathrm{mg} / \mathrm{l})\end{array}$ & $\begin{array}{c}\text { Recuperação } \\
(\%)\end{array}$ \\
$\mathrm{C} 1+\mathrm{C} 2$ & 1,50 & 1,30 & 86,7 \\
$\mathrm{H}+\mathrm{C} 1$ & 2,33 & 2,26 & 97,0 \\
$\mathrm{H}+\mathrm{C} 2$ & 2,82 & 2,76 & 98,0 \\
\hline
\end{tabular}

C1: controle nível 1; C2: controle nível 2; H: homogeneizado.

Os dados obtidos nesse teste, como era esperado, encontram-se na faixa de $80 \%$ a $120 \%$ de recuperação.

\section{Controle da qualidade}

O grau de dispersão dos valores obtidos encontra-se em torno da média de concentração de cistatina $\mathrm{C}$. Os resultados não ultrapassaram os limites estipulados pelo fabricante e foram considerados adequados.

Tabela 5 sob refrigeração [2 a $\left.8^{\circ} \mathrm{C}\right]$ ]

\begin{tabular}{ccccccc}
\hline 1 dia $(\%)$ & 3 dias (\%) & 5 dias $(\%)$ & 7 dias $(\%)$ & 14 dias $(\%)$ & 21 dias $(\%)$ & 28 dias $(\%)$ \\
0,02 & 0,06 & 0,09 & 0,13 & 2,54 & 5,48 & 10,81 \\
0,02 & 0,04 & 0,05 & 0,07 & 3,12 & 5,27 & 11,42 \\
0,01 & 0,01 & 0,02 & 0,04 & 4,19 & 6,18 & 10,20 \\
\hline
\end{tabular}


O controle da qualidade assegurou a precisão dos testes durante todo o ensaio.

\section{FASE B:}

\section{InCLUSÃo de PACIENTES}

Na fase B desste estudo, 197 pacientes transplantados renais preencheram os critérios de inclusão e não apresentaram critérios de exclusão, sendo, portanto, inseridos. Destes, 36 pacientes foram incluídos no grupo 1 (azatioprina [AZA]), 131 no grupo 2 (micofenolato mofetil [MMF]) e 30 no grupo 3 (sirolimus [SRL]). A distribuição é apresentada na Tabela 8.

Tabela 8

\section{Distribuição dos pacientes conforme}

\begin{tabular}{lll}
\hline Grupo & Imunossupressão & $n$ \\
G1 (AZA) & AZA & 09 \\
& AZA/CYA & 22 \\
& AZA/TAC & 05 \\
G2 (MMF) & MMF/CYA & 43 \\
& MMF/TAC & 88 \\
G3 (SRL) & SRL/AZA & 03 \\
& SRL & 09 \\
& SRL/CYA & 05 \\
& SRL/TAC & 03 \\
& SRL/MMF & 10 \\
\hline
\end{tabular}

AZA: azatioprina; CYA: ciclosporina; TAC: tacrolimus; MMF: micofenolato mofetil; SRL: sirolimus.
Não houve diferença estatística entre os grupos no que se refere à maioria das variáveis demográficas. Entretanto, houve diferença com relação a sexo e índice de massa corporal (IMC) entre os grupos 2 e 3 e quanto ao tempo após o transplante entre o grupo 1 e os demais. Os dados demográficos da casuística foram apresentados na Tabela 9 de acordo com os grupos de imunossupressão.

Observaram-se menores correlações entre a recíproca da cistatina $\mathrm{C}$ e a filtração glomerular estimada pelas equações NK, MDRD e CG, quando comparadas àquelas obtidas em relação à creatinina. As menores correlações foram observadas no grupo 1.

A creatinina sérica apresentou correlação homogênea com as equações de estimativa de RFG, independentemente do esquema de imunossupressão usado.

Por outro lado, a cistatina $C$ apresentou correlações que variaram com a equação de estimativa de RFG, assim como com o imunossupressor. A correlação entre cistatina C e NK no grupo AZA foi bem menor que nas demais equações $\mathrm{e}$ nos diferentes grupos.

\section{Discussão}

Validou-se, neste estudo, a técnica de dosagem de cistatina $C$ em nosso centro e estudou-se o impacto dos diferentes imunossupressores antimetabólicos sobre a correlação da concentração sérica de cistatina $C$ e as equações que estimam a filtração glomerular.

Tabela 9 Dados demográficos

\begin{tabular}{ccccc} 
Variável & G1 - AZA & G2 - MPA & G3 - SRL & $p(p=0,05)$ \\
$n$ & 36 & 131 & 30 & - \\
Raça (b/nb) & $29 / 7$ & $88 / 43$ & $29 / 1$ & 0,002 \\
Sexo (f/m) & $25 / 11$ & $43 / 88$ & $11 / 19$ & $<0,001$ \\
Idade no Tx (anos) & $47 \pm 13$ & $41 \pm 13$ & $47 \pm 14$ & 0,062 \\
Peso (kg) & $67,3 \pm 18$ & $64,1 \pm 11,6$ & $70,1 \pm 12,7$ & 0,058 \\
Altura (m) & $1,61 \pm 10$ & $1,62 \pm 9$ & $1,62 \pm 16$ & 0,490 \\
Superfície corpórea (m²) & $1,61 \pm 0,46$ & $1,69 \pm 0,17$ & $1,74 \pm 0,22$ & 0,105 \\
IMC & $25,94 \pm 5,69$ & $23,91 \pm 4,00$ & $27,41 \pm 8,24$ & $*$ \\
Tempo & $140 \pm 111$ & $33 \pm 39$ & $55 \pm 82$ & $* *$ \\
Tx (meses) & & & & \\
Número Tx (1\%/Re) & $35 / 1$ & $117 / 14$ & $29 / 1$ & 0,177 \\
Doador (vivo/falecido) & $19 / 15$ & $69 / 62$ & $14 / 16$ & 0,754 \\
\hline
\end{tabular}

G1: grupo 1; G2: grupo 2; G3: grupo 3; AZA: azatioprina; MPA: ácido micofenólico; SRL: sirolimus; b: branco; nb: não branco; f: feminino; m: masculino; TX: transplante renal; IMC: índice de massa corporal.

*Valor de p: 0,126 (G1/G2), 0,003 (G2/G3) e 0,781 (G1/G3); **valor de p: 0 (G1/G2), 0,284 (G2/G3) e 0 (G1/G3). 
Diversos trabalhos têm sugerido que a cistatina $C$ seja um marcador de RFG superior à creatinina sérica ${ }^{(30,72)}$. Entretanto, nesses estudos, foram utilizados diferentes métodos de dosagem, como RID e EIA, que, em geral, são técnicas que demandam maior tempo de execução, sendo menos precisos e, portanto, apresentando maior dificuldade para implantação na rotina laboratorial|(23).

Neste trabalho, optamos pela padronização da metodologia imunonefelométrica por ser uma técnica rápida, específica, precisa e totalmente automatizada, o que é uma vantagem importante na rotina laboratorial, permitindo maior agilidade na liberação dos resultados e contribuindo para a tomada de decisão na prática clínica.

Os testes desenvolvidos neste estudo apresentaram níveis de precisão intra e interensaio compatíveis com os dados encontrados na literatura e naqueles descritos pelo fabricante do conjunto diagnóstico.

Os testes de validação para o ensaio nefelométrico, realizados em nosso experimento, mostraram CV intraensaio de $3,32 \%$ a 8,93\% e interensaio de 5,38\% a 8,20\%. Em relação à amostra de soro, obteve-se CV intra e interensaio de $8,93 \%$ e $8,20 \%$, respectivamente. Finney et al. obtiveram nos mesmos testes CV de 3\% a 5\%, enquanto Kyhse-Andersen et al. descreveram CV de $2 \%$ a $3,2 \%{ }^{(23,42)}$. De acordo com as normas da ANVISA, variação de até $15 \%$ é considerada aceitável(8,9,59).

Este estudo observou que a cistatina $C$ foi estável por até três dias armazenada à temperatura ambiente. Perda de até $10 \%$ pode ocorrer se a amostra for armazenada por sete dias sem refrigeração. Quando as amostras foram conservadas à temperatura de 2 a $8^{\circ} \mathrm{C}$, mantiveram-se estáveis por até sete dias e com perdas inferiores a $0,13 \%$. Quando as amostras foram mantidas a $-20^{\circ} \mathrm{C}$, a estabilidade foi de até três meses. Esses dados corroboram aqueles já demonstrados anteriormente por Finney et al. ${ }^{(23)}$.

Para a avaliação do limite de detecção, o CV máximo aceitável é de $20 \%$ entre as leituras em replicata( ${ }^{(8)}$. Esse critério foi reproduzido neste trabalho. Encontramos 8,25\% de CV para o teste de limite de detecção.

A sensibilidade analítica deve apresentar CV menor que 15\% para as duplicatas. Neste estudo, obteve-se CV de $14,79 \%$ para sensibilidade analítica ${ }^{(8)}$.

O teste de recuperação mostrou que a perda foi mais pronunciada nos controles comerciais, os quais apresentavam concentração mais baixa que nas amostras de soro. Nossas análises recuperaram $86,7 \%$ da concentração inicial. Esses achados encontram-se nos limites aceitáveis de $80 \%$ a $120 \%{ }^{(9)}$.
Quando as amostras controle foram adicionadas, obteve-se índice de recuperação de $97 \%$ e $98 \%$ nos controles 1 e 2 , respectivamente.

Para a análise do controle da qualidade durante a execução dos ensaios, aplicaram-se os critérios de Westgard et al. ${ }^{(75)}$. Os resultados demonstraram que o método foi reprodutível em todos os ensaios realizados.

A execução do experimento na DLC-HCFMUSP, certificado pelas normas NBR-ISO 9001:2000 e acreditado pelo Programa de Acreditação de Laboratórios Clínicos (PALC) da Sociedade Brasileira de Patologia Clínica/Medicina Laboratorial (SBPC/ML)(2), garantiu a qualidade dos ensaios durante o processo de validação analítica e dos resultados obtidos na segunda fase deste trabalho.

Após a validação da dosagem de cistatina $C$ foi possível a execução da segunda fase do estudo, que consistiu em avaliar se os imunossupressores que interferem na proliferação celular poderiam afetar a correlação entre a concentração sérica de cistatina $\mathrm{C}$ e o RFG.

Desse modo, os imunossupressores AZA, MMF/micofenolato sódico e SRL foram escolhidos por serem antiproliferativos, frequentemente usados em nosso centro.

No entanto, os grupos não se mostraram homogêneos. As principais diferenças encontradas com relação aos dados demográficos foram sexo, raça e tempo pós-transplante e no que se refere ao RFG, foi menor taxa no grupo SRL. O diferente $n$ encontrado em cada grupo de estudo dá-se devido à distribuição existente em nosso centro, de acordo com as diversas terapias pós-transplante utilizadas.

Quanto ao tempo pós-transplante, as modificações nos esquemas imunossupressores, ocorridas nos últimos anos com a crescente substituição do uso de AZA por MMF na terapêutica após o transplante recente, explicam o maior tempo pós-transplante nesse grupo. Do mesmo modo, a prática de tratar nefropatia crônica do enxerto com SRL explica o menor RFG desse grupo.

As diferenças encontradas com relação às doses de imunossupressores utilizadas entre os grupos que usaram MMF são explicadas pelo menor perfil de tolerância à droga quando em associação com SRL, conforme já relatado previamente. Provavelmente a dose de MMF foi mais baixa por toxicidade medular e gastrointestinal $(17,19,27)$.

Não há uma explicação clara para raça e sexo, porém os testes foram ajustados para essas diferenças.

Foi encontrada boa correlação entre a creatinina sérica e a medida do RFG estimada por todas as equações. Esse achado era esperado pelo fato de essas medidas serem 
embasadas em variáveis demográficas, como idade, peso e altura, bem como na creatinina sérica.

No entanto, fica evidente a necessidade de um padrãoouro para determinar o RFG que seja comparado à cistatina $C$, pois a creatinina e suas respectivas fórmulas apresentam inúmeras limitações amplamente abordadas na literatura, como a produção de creatinina pelas células tubulares e o consequente erro de estimativa do verdadeiro RFG, mesmo quando nos referimos às fórmulas derivadas dessa determinação.

$\mathrm{Na}$ análise de regressão linear, a melhor correlação entre marcador de função renal e filtração glomerular estimada pelas diferentes equações foi obtida com a recíproca da creatinina. Por outro lado, a correlação entre as equações com a cistatina $C$ foi baixa em todos os grupos de tratamento, mais expressivamente no grupo 1.

Quando avaliamos os resultados das medidas de filtração glomerular, conforme os grupos de imunossupressores, ficou evidente o comportamento diferenciado da cistatina C quando comparada à creatinina nas correlações com as equações que estimam o RFG. Isso já era esperado, uma vez que a creatinina, mas não a cistatina, participa daquelas equações.

A intenção, no entanto, era avaliar o impacto do imunossupressor sobre a correlação da cistatina com aquelas equações, visto que estas são sempre as mesmas e não se alteram quando se muda a imunossupressão.

Outros fatores que modificam a concentração sérica da cistatina $\mathrm{C}$ foram descritos na literatura, como hormônios tireoidianos, uso de corticosteroides em altas doses ou presença de doença neoplásica ${ }^{(28,40,64)}$.

Risch et al. compararam o uso de cistatina C em pacientes antes e depois da pulsoterapia com corticoides e verificaram que existe elevação significativa dos valores de concentração sérica de cistatina $C$ após três dias do início do tratamento e esse acréscimo não estava relacionado com o prejuízo de função renal. Bökenkamp et al. verificaram que a interferência com a dosagem de cistatina $C$ pode estar relacionada diretamente com a droga imunossupressora utilizada ou com algum metabólito produzido pela imunossupressão $0^{(3,64)}$.

Em nossa casuística, as doses de corticosteroides foram, em média, baixas e semelhantes, o que indica que esse fator provavelmente não interferiu.

Em nosso estudo, não encontramos diferenças nas correlações de cistatina C e RFG de acordo com o antiproliferativo usado.
Houve menor correlação de cistatina $\mathrm{C}$ e NK no grupo $A Z A$, o que não foi reproduzido nas demais equações.

É possível que esse comportamento diferenciado da cistatina $C$, segundo a imunossupressão, possa decorrer da interferência da AZA ou de seus metabolitos na produção ou metabolização da cistatina C. A AZA interfere no metabolismo nuclear de todas as células, enquanto os modernos imunossupressores (SRL e MMF) têm maior ação sobre a proliferação linfocitária.

Outros estudos serão necessários para a elucidação dos mecanismos envolvidos. Dessa forma, a aplicação clínica da cistatina $C$ em pacientes sob essa imunossupressão pode ser limitada. Porém, vale lembrar que o $n$ pode ter sido um fator determinante neste estudo e que, para maiores discussões, talvez fosse necessária uma população maior utilizando esse esquema terapêutico.

Uma limitação do trabalho foi não termos utilizado uma medida direta de filtração glomerular, cuja mensuração fosse independente da creatinina sérica. Por isso, não podemos afirmar, de forma definitiva, a inferioridade da cistatina $\mathrm{C}$ em relação à creatinina sérica enquanto marcadores de filtração glomerular. Mais uma vez, cabe ressaltar a importância da inclusão de um marcador de filtração glomerular de referência (padrão-ouro) que seja independente da determinação de creatinina, como $\mathrm{Cr}$ EDTA ou inulina, para que possamos eliminar os fatores interferentes e realizarmos comparações efetivas.

Este trabalho sugere que as drogas imunossupressoras antiproliferativas parecem não interferir na determinação do nível sérico da cistatina $C$ independente do RFG.

A utilização de uma metodologia com mensuração direta da filtração glomerular independente de creatinina é imprescindível para a avaliação do desempenho da cistatina $\mathrm{C}$ em diferentes esquemas imunossupressores.

\section{Conclusão}

A cistatina $C$ atendeu todos os critérios preconizados pelas agências regulatórias para validação do método e sua implantação na rotina laboratorial na DLC é factível.

A recíproca da creatinina apresentou a melhor correlação com as equações que estimam a função renal independente do grupo de imunossupressor.

A cistatina $C$ apresentou menores correlações com essas equações em todos os grupos de imunossupressores. 


\section{Referências}

1. ABRAHAMSON, M.; GRUBB, A. Increased body temperature accelerates aggregation of the Leu-68-->GIn mutant cystatin C, the amyloid-forming protein in hereditary cystatin $\mathrm{C}$ amyloid angiopathy. Proc Natl Acad Sci USA, v. 91, n. 4, p. 1416-20, 1994.

2. ASSOCIAÇÃO BRASILEIRA DE NORMAS TÉCNICAS. NBRISO 9001: sistema de gestão da qualidade, requisitos. Rio de Janeiro, 2000.

3. BÖKENKAMP, A. et al. Cystatin C serum concentrations underestimate glomerular filtration rate in renal transplant recipients. Clin Chem, v. 45, n. 10, p. 1866-8, 1999.

4. BÖKENKAMP, A. et al. Reference values for cystatin C serum concentrations in children. Pediatr Nephrol, v. 12, n. 2, p. 125-9, 1998.

5. BÖKENKAMP, A. et al. The beta2-microglobulin/cystatin $C$ ratio - a potential marker of post-transplant lymphoproliferative disease. Clin Nephrol, v. 58, n. 6, p. 417-22, 2002.

6. BÖKENKAMP, A.; HERGET-ROSENTHAL, S.; BÖKENKAMP, R. Cystatin $C$, kidney function and cardiovascular disease. Pediatr Nephrol, v. 21, n. 9, p. 1223-30, 2006.

7. BOUVET, Y. et al. GFR is better estimated by considering both serum cystatin $\mathrm{C}$ and creatinine levels. Pediatr Nephrol, v. 21, n. 9, p. 1299-306, 2006.

8. BRASIL. Ministério da Saúde. Agência Nacional de Vigilância Sanitária. Medicamentos ICdBL. Resolução n. 899, de 29 de maio de 2003, Guia para a validação de métodos analíticos e bioanalíticos. Disponível em: $<$ www.anvisa.gov.br>.

9. BRASIL. Resolução n. 899, de 29 de maio de 2003, Guia para validação de métodos analíticos e bioanalíticos. Brasil, 2003.

10. CHANTREL, F. et al. Comparison of cystatin $C$ versus creatinine for detection of mild renal failure. Clin Nephrol, v. 54, n. 5, p. 374-81, 2000.

11. CLINICAL AND LABORATORY STANDARDS INSTITUTE. Evaluation of precision performance of clinical chemistry devices - EP5-A2; Approved Guideline, $2^{\text {nd }}$ ed., Wayne, Pennsylvania, 2006. p. 48.

12. CLINICAL LABORATORY IMPROVEMENT ACT PROGRAM FREE COLLECTION - HCFA. Final rule with comment. Fed Regist, v. 57, n. 40, p. 7188-218, 1992.

13. CLINICAL LABORATORY IMPROVEMENT AMENDMENTS. Final rule laboratory requirements federal register. p. 7002-288, 1992

14. COCKCROFT, D. W.; GAULT, M. H. Prediction of creatinine clearance from serum creatinine. Nephron, v. 16, n. 1, p. 31-41, 1976.

15. COLL, E. et al. Serum cystatin C as a new marker for noninvasive estimation of glomerular filtration rate and as a marker for early renal impairment. Am J Kidney Dis, v. 36, n. 1, p. 29-34, 2000.

16. DHARNIDHARKA, V. R.; KWON, C.; STEVENS, G. Serum cystatin $\mathrm{C}$ is superior to serum creatinine as a marker of kidney function: a meta-analysis. Am J Kidney Dis, v. 40 , n. 2, p. 221-6, 2002.
17. DIEKMANN, F. et al. Conversion to rapamycin in renal allograft recipients with biopsy-proven calcineurin inhibitor-induced nephrotoxicity. Transplant Proc, v. 33, n. 7-8, p. 3234-5, 2001.

18. DWORKIN, L. D. Serum cystatin C as a marker of glomerular filtration rate. Curr Opin Nephrol Hypertens, v. 10, n. 5, p. 551-3, 2001.

19. EGIDI, M. F. et al. Conversion to sirolimus in solid organ transplantation: a single-center experience. Transplant Proc, v. 35, n. 3(Suppl), p. 131S-7S, 2003.

20. FILLER, G. et al. Cystatin C as a marker of GFR: history, indications, and future research. Clin Biochem, v. 38, n. 1, p. 1-8, 2005.

21. FILLER, G. et al. The Cockcroft-Gault formula should not be used in children. Kidney Int, v. 67, n. 6, p. 2321-4, 2005.

22. FILLER, G.; LEPAGE, N. Should the Schwartz formula for estimation of GFR be replaced by cystatin $C$ formula? Pediatr Nephrol, v. 18, n. 10, p. 981-5, 2003.

23. FINNEY, H. etal. Initial evaluation of cystatin $\mathrm{C}$ measurement by particle-enhanced immunonephelometry on the Behring nephelometer systems (BNA, BN II). Clin Chem, v. 43, n. 6, p. 1016-22, 1997.

24. FINNEY, H.; NEWMAN, D. J.; PRICE, C. P. Adult reference ranges for serum cystatin $\mathrm{C}$, creatinine and predicted creatinine clearance. Ann Clin Biochem, v. 37, n. 1, p. 49-59, 2000.

25. FINNEY, H.; WILLIAMS, A. H.; PRICE, C. P. Serum cystatin C in patients with myeloma. Clin Chim Acta, v. 309, n. 1, p. 1-6, 2001.

26. FISCHBACH, M. et al. Impact of age on reference values for serum concentration of cystatin $\mathrm{C}$ in children. Pediatr Nephrol, v. 17, n. 2, p. 104-6, 2002.

27. FLECHNER, S. M. et al. The effect of 2-gram versus 1-gram concentration controlled mycophenolate mofetil on renal transplant outcomes using sirolimus-based calcineurin inhibitor drug-free immunosuppression. Transplantation, v. 79, n. 8, p. 926-34, 2005.

28. FRICKER, M. et al. Impact of thyroid dysfunction on serum cystatin C. Kidney Int, v. 63, n. 5, p. 1944-7, 2003.

29. GASPARI, F.; PERICO, N.; REMUZZI, G. Measurement of glomerular filtration rate. Kidney Int Suppl, n. 63, p. S151-4, 1997.

30. GRUBB, A. Diagnostic value of analysis of cystatin $C$ and protein HC in biological fluids. Clin Nephrol, v. 38, Suppl 1, p. S20-7, 1992.

31. GUPTA-MALHOTRA, M. et al. Decreased levels of cystatin $C$, an inhibitor of the elastolytic enzyme cysteine protease, in acute and subacute phases of kawasaki disease. Cardiology, v. 99, n. 3, p. 121-5, 2003.

32. HARIHARAN, S. et al. Post-transplant renal function in the first year predicts long-term kidney transplant survival. Kidney Int, v. 62, n. 1, p. 311-8, 2002.

33. HOEK, F. J.; KEMPERMAN, F. A.; KREDIET, R. T. A comparison between cystatin $\mathrm{C}$, plasma creatinine and the Cockcroft and Gault formula for the estimation of glomerular filtration rate. Nephrol Dial Transplant, v. 18, n. 10, p. 2024-31, 2003. 
34. HUTCHENS, T. T. NCCLS: objectives, organization, and activities. Pathologist, v. 35, n. 11, p. 605-8, 1981.

35. JERNBERG, T. et al. Cystatin C: a novel predictor of outcome in suspected or confirmed non-ST-elevation acute coronary syndrome. Circulation, v. 110, n. 16, p. 2342-8, 2004.

36. KEITGES, P. W. NCCLS: developing voluntary consensus standards for the clinical laboratory. Pathologist, v. 33, n. 2, p. 86-8, 1979.

37. KILPATRICK, E. S.; KEEVIL, B. G.; ADDISON, G. M. Does adjustment of GFR to extracellular fluid volume improve the clinical utility of cystatin C? Arch Dis Child, v. 82, n. 6, p. 499-502, 2000.

38. KNIGHT, E. L. et al. Factors influencing serum cystatin $C$ levels other than renal function and the impact on renal function measurement. Kidney Int, v. 65, n. 4, p. 1416-21, 2004.

39. KOS, J. et al. Cathepsins $B, H$, and $L$ and their inhibitors stefin $A$ and cystatin $C$ in sera of melanoma patients. Clin Cancer Res, v. 3, n. 10, p. 1815-22, 1997.

40. KOS, J. et al. Serum cystatin C, a new marker of glomerular filtration rate, is increased during malignant progression. Clin Chem, v. 44, n. 12, p. 2556-7, 1998.

41. KOURI, T. et al. Reference intervals for the markers of proteinuria with a standardised bed-rest collection of urine. Clin Chem Lab Med, v. 39, n. 5, p. 418-25, 2001.

42. KYHSE-ANDERSEN, J. et al. Serum cystatin C, determined by a rapid, automated particle-enhanced turbidimetric method, is a better marker than serum creatinine for glomerular filtration rate. Clin Chem, v. 40, n. 10, p. 1921-6, 1994.

43. LATERZA, O. F.; PRICE, C. P.; SCOTT, M. G. Cystatin C: an improved estimator of glomerular filtration rate? Clin Chem, v. 48, n. 5, p. 699-707, 2002.

44. LE BRICON, T. et al. Changes in plasma cystatin $\mathrm{C}$ after renal transplantation and acute rejection in adults. Clin Chem, v. 45, n. 12, p. 2243-9, 1999.

45. LEACH, T. D. et al. Prognostic significance of serum cystatin $\mathrm{C}$ concentrations in renal transplant recipients: 5-year follow-up. Transplant Proc, v. 34, n. 4, p. 1152-8, 2002.

46. LEVEY, A. S. et al. A more accurate method to estimate glomerular filtration rate from serum creatinine: a new prediction equation. Modification of Diet in Renal Disease Study Group. Ann Intern Med, v. 130, n. 6, p. 461-70, 1999.

47. LEVEY, A. S. et al. Creatinine filtration, secretion and excretion during progressive renal disease. Modification of Diet in Renal Disease (MDRD) Study Group. Kidney Int Suppl, v. 27, p. S73-80, 1989.

48. MARES, J. et al. Use of cystatin C determination in clinical diagnostics. Biomed Pap Med Fac Univ Palacky Olomouc Czech Repub, v. 147, n. 2, p. 177-80, 2003.

49. Medicare, Medicaid, and Clinical Laboratories Improvement Act (CLIA) patient confidentiality rules; proposed rule. Fed Regist, v. 53, n. 62, p. 10404-6, 1988.

50. MUSSAP, M. et al. Cystatin $C$ is a more sensitive marker than creatinine for the estimation of GFR in type 2 diabetic patients. Kidney Int, v. 61, n. 4, p. 1453-61, 2002.

51. MUSSAP, M. et al. Quantitative automated particleenhanced immunonephelometric assay for the routinary measurement of human cystatin C. Clin Chem Lab Med, v. 36, n. 11, p. $859-65,1998$.

52. NANKIVELL, B. J. et al. Predicting glomerular filtration rate after kidney transplantation. Transplantation, v. 59, n. 12, p. 1683-9, 1995.

53. NATIONAL COMMITTEE ON CLINICAL LABORATORY STANDARDS. Evaluation of precision performance of clinical chemistry devices - EP5-T2. Approved Guideline. Wayne, Pennsylvania, 1999. p. 43.

54. NATIONAL COMMITTEE FOR CLINICAL LABORATORY STANDARDS. Precision performance of clinical chemistry devices - EP5-T2. Proposed Guideline. Villanova, Pennsylvania, 1999.

55. NEWMAN, D. J. et al. Serum cystatin C: a replacement for creatinine as a biochemical marker of GFR. Kidney Int Suppl, n. 47, p. S20-1, 1994.

56. O'RIORDAN, S. et al. Serum cystatin $C$ is not a better marker of creatinine or digoxin clearance than serum creatinine. Br J Clin Pharmacol, v. 53, n. 4, p. 398-402, 2002.

57. ODDOZE, C. et al. Cystatin C is not more sensitive than creatinine for detecting early renal impairment in patients with diabetes. Am J Kidney Dis, v. 38, n. 2, p. 310-6, 2001.

58. PAGE, M. K. et al. Clinical value of cystatin $C$ determination. Clin Chim Acta, v. 297, n. 1-2, p. 67-72, 2000.

59. PAINTER, P. Clinical chemistry. Laboratory management and clinical correlations. Lippincott Willians \& Wilkings, 2002. p. 122-51.

60. PERALTA, C. A. et al. African ancestry, socioeconomic status, and kidney function in elderly African Americans: a genetic admixture analysis. J Am Soc Nephrol, v. 17, n. 12, p. 3491-6, 2006.

61. PIERRAT, A. et al. Predicting GFR in children and adults: a comparison of the Cockcroft-Gault, Schwartz, and modification of diet in renal disease formulas. Kidney Int, v. 64, n. 4, p. 1425-36, 2003.

62. POGE, U. et al. Cystatin C-based calculation of glomerular filtration rate in kidney transplant recipients. Kidney Int, v. 70, n. 1, p. 204-10, 2006.

63. RANDERS, E. et al. Serum cystatin $\mathrm{C}$ as an endogenous parameter of the renal function in patients with normal to moderately impaired kidney function. Clin Nephrol, v. 54, n. 3, p. 203-9, 2000.

64. RISCH, L. etal. Effects of glucocorticoid immunosuppression on serum cystatin $\mathrm{C}$ concentrations in renal transplant patients. Clin Chem, v. 47, n. 11, p. 2055-9, 2001.

65. RISCH, L.; HUBER, A. R. Assessing glomerular filtration rate in renal transplant recipients by estimates derived from serum measurements of creatinine and cystatin C. Clin Chim Acta, v. 356, n. 1-2, p. 204-11, 2005.

66. RODRIGO, E. et al. Measurement of renal function in preESRD patients. Kidney Int Suppl, n. 80, p. 11-7, 2002.

67. SCHWARTZ, G. J.; FURTH, S. L. Glomerular filtration rate measurement and estimation in chronic kidney disease. Pediatr Nephrol, v. 22, n. 11, p. 1839-48, 2007.

68. SELIGER, S. L. etal. Cystatin $\mathrm{C}$ and subclinical brain infarction. J Am Soc Nephrol, v. 16, n. 12, p. 3721-7, 2005.

69. SHIMIZU-TOKIWA, A. et al. Serum cystatin $C$ is a more sensitive marker of glomerular function than serum creatinine. Nephron, v. 92, n. 1, p. 224-6, 2002. 
70. SHLIPAK, M. G. et al. Cystatin C and mortality risk in the elderly: the health, aging, and body composition study. J Am Soc Nephrol, v. 17, n. 1, p. 254-61, 2006.

71. SHLIPAK, M. G.; PRAUGHT, M. L.; SARNAK, M. J. Update on cystatin $\mathrm{C}$ : new insights into the importance of mild kidney dysfunction. Curr Opin Nephrol Hypertens, v. 15, n. 3, p. 270-5, 2006.

72. SIMONSEN, O.; GRUBB, A.; THYSELL, H. The blood serum concentration of cystatin $\mathrm{C}$ (gamma-trace) as a measure of the glomerular filtration rate. Scand J Clin Lab Invest, v. 45, n. 2, p. 97-101, 1985.
73. STREVENS, H. et al. Serum cystatin $\mathrm{C}$ reflects glomerular endotheliosis in normal, hypertensive and pre-eclamptic pregnancies. Bjog, v. 110, n. 9, p. 825-30, 2003.

74. SWEDKO, P. J. et al. Serum creatinine is an inadequate screening test for renal failure in elderly patients. Arch Intern Med, v. 163, n. 3, p. 356-60, 2003.

75. WESTGARD, J. O. et al. A multi-rule Shewhart chart for quality control. Clin Chem, v. 27, p. 493-501, 1981.

76. WILLEMS, H. L. et al. Is serum cystatin $\mathrm{C}$ the marker of choice to predict glomerular filtration rate in paediatric patients? Ann Clin Biochem, v. 40, n. 1, p. 60-4, 2003. 